\title{
Simultaneous observations by sky radiometer and MAX-DOAS for characterization of biomass burning plumes in central Thailand in January-April 2016
}

\author{
Hitoshi Irie $^{1}$, Hossain Mohammed Syedul Hoque ${ }^{1}$, Alessandro Damiani ${ }^{1}$, Hiroshi Okamoto ${ }^{1}$, Al Mashroor Fatmi $^{1}$, \\ Pradeep Khatri $^{2}$, Tamio Takamura ${ }^{1}$, and Thanawat Jarupongsakul ${ }^{3}$ \\ ${ }^{1}$ Center for Environmental Remote Sensing, Chiba University, 1-33 Yayoicho, Inage-ku, Chiba 263-8522, Japan \\ ${ }^{2}$ Center for Atmospheric and Oceanic Studies, Graduate School of Science, Tohoku University, Sendai 980-8578, Japan \\ ${ }^{3}$ Department of Geology, Faculty of Science, Chulalongkorn University, Phayathai Road, Bangkok 10330, Thailand
}

Correspondence: Hitoshi Irie (hitoshi.irie@ chiba-u.jp)

Received: 23 August 2018 - Discussion started: 13 September 2018

Revised: 26 December 2018 - Accepted: 15 January 2019 - Published: 29 January 2019

\begin{abstract}
The first intensive multicomponent ground-based remote-sensing observations by sky radiometer and multiaxis differential optical absorption spectroscopy (MAXDOAS) were performed simultaneously at the SKYNET Phimai site located in central Thailand $\left(15.18^{\circ} \mathrm{N}, 102.56^{\circ} \mathrm{E}\right)$ from January to April 2016. The period corresponds to the dry season associated with intense biomass burning (BB) activity around the site. The near-surface concentration of formaldehyde (HCHO) retrieved from MAX-DOAS was found to be a useful tracer for absorption aerosols from BB plumes, when $\mathrm{BB}$ was the dominant source of $\mathrm{HCHO}$ and absorption aerosols over other sources. As the HCHO concentration tripled from 3 to 9 ppbv, the ratio of gaseous glyoxal to HCHO concentrations in daytime decreased from $\sim 0.04$ to $\sim 0.03$, responding presumably to the increased contribution of volatile organic compound emissions from BB. In addition, clear increases in aerosol absorption optical depths (AAODs) retrieved from sky radiometer observations were seen with the $\mathrm{HCHO}$ enhancement. At a $\mathrm{HCHO}$ of $9 \mathrm{ppbv}$, AAOD at a wavelength of $340 \mathrm{~nm}$ reached as high as $\sim 0.15 \pm 0.03$. The wavelength dependence of AAODs at 340-870 nm was quantified by the absorption Ångström exponent (AAE), providing evidence for the presence of brown carbon aerosols at an AAE of $1.5 \pm 0.2$. Thus, our multicomponent observations around central Thailand are expected to provide unique constraints for understanding physicalchemical-optical properties of BB plumes.
\end{abstract}

\section{Introduction}

It is well recognized that aerosols contribute the largest uncertainty to the estimate of radiative forcing (e.g., IPCC, 2013). Biomass burning (BB) is a substantial source of aerosols to the atmosphere. Black carbon (BC) is a strongly light-absorbing component of aerosols and can be emitted in large quantities from BB. In addition, about two-thirds of the global primary organic aerosol $(\mathrm{OA})$ that should comprise a large amount of ultraviolet (UV)-light-absorbing OA, known as brown carbon $(\mathrm{BrC})$, originates from $\mathrm{BB}$ plumes (Bond et al., 2013). Currently, most climate models treat OA as purely scattering. Recent laboratory studies suggested that $\mathrm{BrC}$ can enhance net absorption by $\mathrm{OA}$, potentially altering the $\mathrm{BB}$ direct radiative forcing from negative to positive (Kirchstetter et al., 2004; Saleh et al., 2014). Moreover, underestimation in aerosol absorption over most BB regions was reported by Hammer et al. (2016), who used a global 3 -D chemistry transport model (GEOS-Chem), in which OA is regarded as purely scattering. Thus, the potential climate effects of $\mathrm{BrC}$ aerosols have received considerable attention recently (e.g., Myhre et al., 2013). In addition, as a result of UV absorption, tropospheric photochemistry can be significantly affected; GEOS-Chem simulation incorporating UV absorption by $\mathrm{BrC}$ showed a decrease in tropospheric hydroxyl radical $(\mathrm{OH})$ concentration by up to $15 \%$ for $\mathrm{BB}$ regions, compared to the simulation without UV absorption by $\mathrm{BrC}$ (Hammer et al., 2016). BrC comprises a wide range of poorly characterized compounds that exhibit highly variable 
absorptivity. Assessing the role of $\mathrm{BrC}$ in light absorption is further difficult because $\mathrm{BrC}$ is not only emitted as a primary organic aerosol (POA) but also produced as a secondary organic aerosol (SOA) through complex formation processes from volatile organic compounds (VOCs) originating from BB.

This study focuses on the intense BB activity that occurred around central Thailand from January to April 2016. Characterization for the BB plumes is attempted using our unique remote-sensing observations by the sky radiometer (e.g., Nakajima et al., 1996) and the multi-axis differential optical absorption spectroscopy (MAX-DOAS) (e.g., Irie et al., 2011) for both viewpoints of the optical properties of aerosols (aerosol absorption optical depth, AAOD, and absorption Ångström exponent, AAE) and the organic gas concentrations (formaldehyde, $\mathrm{HCHO}$, and glyoxal, $\mathrm{CHOCHO}$ ) in BB plumes.

\section{Observation}

We conducted ground-based remote-sensing observations using the sky radiometer and the MAX-DOAS at the SKYNET Phimai site $\left(15.18^{\circ} \mathrm{N}, 102.56^{\circ} \mathrm{E}\right)$ located in central Thailand from January to April 2016. The period corresponds to the dry season with the occurrence of intense BB around the site. Indeed, satellite data revealed evident enhancements in the carbon monoxide column concentration and the fire radiative power (FRP) around the SKYNET Phimai site in the dry season (Hoque et al., 2018a, b). Concerning the sky radiometer and the MAX-DOAS, their instrumentation, data analysis, and retrieval are described below.

\subsection{Sky radiometer observation of aerosol optical properties}

The sky radiometer (POM-02; Prede Co., Ltd., Tokyo, Japan), a sun-sky photometer measuring direct and diffuse solar irradiances, is the main instrument of the international ground-based remote-sensing network SKYNET (e.g., Takamura and Nakajima, 2004; Nakajima et al., 2007). Measurements of the direct solar and diffuse irradiances within $160^{\circ}$ of the center of the Sun were conducted every $10 \mathrm{~min}$. Values of aerosol optical depth (AOD), single-scattering albedo (SSA), and refractive index at 340, 380, 400, 500, 675, and $870 \mathrm{~nm}$ were retrieved using the sky radiometer analysis package from the Center for Environmental Remote Sensing (SR-CEReS) version 1 (Mok et al., 2018), in which SKYRAD.pack version 5 (Hashimoto et al., 2012) is implemented to retrieve aerosol properties, along with all pre- and post-processing programs for the purpose of near-real-time data delivery. Data at $1020 \mathrm{~nm}$ were not used in this study to avoid possible impact by low AAOD and interference by water vapor $\left(\mathrm{H}_{2} \mathrm{O}\right)$ on the estimate of the AAE. Cloud screening was carried out using the method of Khatri and Taka- mura (2009) but without using global irradiance data from a pyranometer.

The SKYNET sky radiometer has on-site calibration methods, namely the improved Langley (IL) method determining the calibration constant $\left(F_{0}\right)$ (e.g., Campanelli et al., 2007) and the solar disk scan (SDS) method determining the solid view angle (SVA) (e.g., Nakajima et at., 1996; Uchiyama et al., 2018). Recently, Mok et al. (2018) used retrievals with SR-CEReS to compare SKYNET sky radiometer AOD and SSA data with those derived from a combination of Aerosol Robotic Network (AERONET), multifilter rotating shadow-band radiometer (MFRSR), and Pandora observations in Seoul, Korea, during and after the NASA KORUS-AQ (Korea-US Air Quality) campaign in 2016 (Mok et al., 2018, and references therein). For most cases, their agreements were found to be within \pm 0.01 and \pm 0.05 for AOD and SSA data, respectively, at all wavelengths from 340 to $870 \mathrm{~nm}$, supporting the ability of the on-site calibration methods using IL and SDS.

Since the importance of accurate SVA determination was particularly pointed out to better interpret the difference seen in previous SSA comparisons between SKYNET and AERONET (Khatri et al., 2016), sensitivity analysis was performed in the present study by conducting additional retrievals using SVAs offset by $\pm 0.01 \mathrm{msr}(\sim \pm 4 \%)$, which is likely to correspond to the uncertainty in SVA determined by a single SDS. Both positive and negative offsets were tested but only the positive offset is discussed here because the negative offset tended to show only little or no impact on SSA, when SSA was close to unity. This is because a smaller SVA leads to a larger SSA (Hashimoto et al., 2012). The impacts by the SVA offset of $+0.01 \mathrm{msr}$ on SSAs were estimated to be as small as $-0.010 \pm 0.005,-0.010 \pm 0.005,-0.010 \pm$ $0.005,-0.010 \pm 0.006,-0.012 \pm 0.007$, and $-0.011 \pm 0.008$ at $340,380,400,500,675$, and $870 \mathrm{~nm}$, respectively. Thus, overestimation (underestimation) in SVA leads to underestimation (overestimation) in SSA, but the magnitude was found to be very small at about \pm 0.01 , when the uncertainty in SVA was $\sim \pm 0.01 \mathrm{msr}$. The small impact on SSAs should be a result of compensation by the associated change in $F_{0}$ values; using SVA values offset by $+0.01 \mathrm{msr}$ as an input, the IL method employed in SR-CEReS yields smaller $F_{0}$ values by about $2.1 \pm 0.1 \%, 1.8 \pm 0.2 \%, 1.7 \pm 0.2 \%, 1.2 \pm 0.2 \%$, $0.7 \pm 0.2 \%$, and $0.5 \pm 0.1 \%$ for $340,380,400,500,675$, and $870 \mathrm{~nm}$, respectively. The resulting smaller $F_{0}$ leads to a larger SSA (Hashimoto et al., 2012), which is an opposite trend in the direct impact that a larger SVA leads to a smaller SSA (Hashimoto et al., 2012). Results from these sensitivity analyses support the agreement of SSAs within \pm 0.05 seen in recent comparisons by Mok et al. (2018) during and after the NASA KORUS-AQ campaign.

Using the AOD and SSA data retrieved, AAOD and AAE values were derived as follows. First, for each measurement and for respective wavelengths from 340 to $870 \mathrm{~nm}$, the AAOD value and its uncertainty $\left(\varepsilon_{\mathrm{AAOD}}\right)$ were calculated 
with the following equations.

$$
\begin{aligned}
& \operatorname{AAOD}(\lambda)=\operatorname{AOD}(\lambda) \cdot[1-\operatorname{SSA}(\lambda)] \\
& \varepsilon_{\mathrm{AAOD}(\lambda)}=\sqrt{\left[(1-\operatorname{SSA}(\lambda)) \cdot \varepsilon_{\mathrm{AOD}}\right]^{2}+\left(\operatorname{AOD}(\lambda) \cdot \varepsilon_{\mathrm{SSA}}\right)^{2}}
\end{aligned}
$$

For the estimate of $\varepsilon_{\operatorname{AAOD}(\lambda)}$, uncertainties for $\operatorname{AOD}(\lambda)$ and $\operatorname{SSA}(\lambda)\left(\varepsilon_{\mathrm{AOD}}\right.$ and $\left.\varepsilon_{\mathrm{SSA}}\right)$ were assumed to be 0.01 and 0.05 , respectively, based on comparisons by Mok et al. (2018). Since the comparisons by Mok et al. (2018) were made using independent measurements having uncertainties of the same order of magnitude, the actual uncertainties in sky radiometer AOD and SSA data would be smaller. AAE is calculated as the slope of the linear fit of $\ln [\operatorname{AAOD}(\lambda)]$ versus $\ln (\lambda)$ :

$\ln [\mathrm{AAOD}(\lambda)]=a-\mathrm{AAE} \cdot \ln (\lambda)$,

where $a$ is an intercept. This equation is equivalent to expression using the power law:

$\operatorname{AAOD}(\lambda)=K \lambda^{-\mathrm{AAE}}$,

where $K$ is a constant. To exclude AAE data associated with large uncertainty, only the data that satisfy the criteria that (1) $\operatorname{AAOD}(\lambda)$ exceeds $\varepsilon_{\operatorname{AAOD}(\lambda)}$ for all wavelengths and (2) the correlation coefficient of the linear fit $(R)$ is high $(-1.0 \leq R \leq-0.9)$ are used in the analysis below. To refine the data set of AOD, SSA, AAOD, and AAE with reduced uncertainty, the daily mean and its standard deviation with more than four data were calculated for 09:00-15:00 LT.

\subsection{MAX-DOAS observation of trace gases}

The MAX-DOAS is an instrument measuring UV-visible spectra of scattered sunlight at several elevation angles between the horizon and zenith (e.g., Hönninger and Platt, 2002; Hönninger et al., 2004; Irie et al., 2015). Its measurement is based on the well-established DOAS technique that quantitatively detects narrow band absorption by trace gases by applying the Lambert-Beer law (e.g., Platt and Stutz, 2008). Since the pioneering study by Hönninger and Platt (2002) and Hönninger et al. (2004), various types of instruments and algorithms for MAX-DOAS have been developed worldwide. One of the reasons for this is because ground-based MAX-DOAS observations at a low elevation angle provide enhanced signals of concentrations of important trace gases in the boundary layer (i.e., around the instrument altitude) and the concentrations can be interpreted as being the average over a distance, which is on the same order of or finer than the horizontal resolution of models and satellite observations but coarser than that of in situ observations (Irie et al., 2011).

From January to April 2016, our MAX-DOAS system (Prede Co., Ltd) (Irie et al., 2011; Hoque et al., 2018a, b) was operated continuously at the SKYNET Phimai site together with the sky radiometer. It was combined with the spectrometer Maya2000 Pro (Ocean Optics, Inc.) (with a slit of $25 \mu \mathrm{m}$ ) embedded in a temperature-controlled box to record highresolution spectra (with the full width at half maximum of around $0.3-0.4 \mathrm{~nm}$ and the oversampling of 3-4) from 310 to $515 \mathrm{~nm}$. Measurements were made at six elevation angles of $2,3,4,6,8$, and $70^{\circ}$ every $30 \mathrm{~min}$. Instead of $90^{\circ}$, the $70^{\circ} \mathrm{el}-$ evation angle was adopted as reference to reduce a variation range of signals measured at all the elevation angles, while the integration time was kept constant. MAX-DOAS off-axis elevation angle measurements were limited to below $10^{\circ}$ for minimizing the possible systematic error in oxygen collision complex fitting results but keeping the measurement sensitivity in the lowest layer of vertical profiles retrieved high (Irie et al., 2015).

Spectral analysis by the so-called DOAS method (Platt and Stutz, 2008) for spectral fitting using the nonlinear leastsquares method and the subsequent vertical profile retrievals using the optimal estimation method were performed by our retrieval algorithm, JM2 (Japanese MAX-DOAS profile retrieval algorithm, version 2) (e.g., Irie et al., 2008, 2011, 2015). Using the recorded high-resolution UV-visible spectra from 310 to $515 \mathrm{~nm}$, the JM2 allows us to retrieve lowertropospheric vertical profile information for eight quantities, including $\mathrm{HCHO}, \mathrm{CHOCHO}$, nitrogen dioxide $\left(\mathrm{NO}_{2}\right)$, and $\mathrm{H}_{2} \mathrm{O}$ concentrations, which are analyzed below. We used fitting windows and cross-section data identical to those described by Irie et al. $(2011,2015)$ and Hoque et al. (2018a). The residual for DOAS fitting was usually as low as below $10^{-3}$. In the vertical profile retrieval, the elevation angle setting was fully considered in the computation of differential air mass factors (e.g., Irie et al., 2011, 2015). The input parameters used for the vertical profile retrievals are the same as those used by Irie et al. (2015) for Cabauw, the Netherlands. The degrees of freedom for signal for trace gas vertical profiles retrieved here were usually $1-2$. Of vertical profiles retrieved, the present study analyzed data for a layer of $0-1 \mathrm{~km}$, which corresponds to the lowest layer with the highest sensitivity owing to the longest light path in profiles retrieved by JM2. The total uncertainties, including random and systematic errors, were estimated to be $24 \%$ (HCHO), $19 \%$ (CHO$\mathrm{CHO}), 15 \%\left(\mathrm{NO}_{2}\right)$, and $18 \%\left(\mathrm{H}_{2} \mathrm{O}\right)$ (Irie et al., 2011). For $\mathrm{HCHO}\left(\mathrm{CHOCHO}, \mathrm{NO}_{2}\right.$, and $\left.\mathrm{H}_{2} \mathrm{O}\right)$ retrievals, the systematic error was estimated by conducting additional retrievals as JM2 aerosol retrieval uncertainties of $50 \%(30 \%)$, in which uncertainty due to assuming fixed SSA values should be included (Irie et al., 2008, 2011; Hoque et al., 2018a, b). Using the retrieved $\mathrm{H}_{2} \mathrm{O}$ concentration, the relative humidity over water $\left(\mathrm{RH}_{\mathrm{W}}\right)$ for the layer at $0-1 \mathrm{~km}$ was estimated using NCEP (National Centers for Environmental Prediction) pressure and temperature reanalysis data $\left(2.5^{\circ}\right.$ grid and 6-hourly). To be consistent with sky radiometer data, the daily mean values for 09:00-15:00 LT are analyzed in this study. More detailed descriptions about MAX-DOAS, including fitting windows and cross-section data, are given by Irie et al. (2011, 2015), Hoque et al. (2018a, b), and references therein. 


\section{Results and discussion}

Time series of multiple components retrieved from sky radiometer and MAX-DOAS observations at the SKYNET Phimai site for the intense biomass burning period from January to April 2016 is shown in Fig. 1. As seen in Fig. 1, $\mathrm{RH}_{\mathrm{w}}$ for a layer of $0-1 \mathrm{~km}$ derived from MAX-DOAS observations and the surface $\mathrm{RH}_{\mathrm{w}}$ from NCEP data confirm that the period was dry around Phimai, particularly from the beginning of February through the middle of April (from days 32 to 110). For the period of January-April 2016, mean AOD values at 340,500 , and $865 \mathrm{~nm}$ were high at $0.98 \pm 0.41$, $0.64 \pm 0.27$, and $0.27 \pm 0.11$, respectively. The AOD values reached the peak in late March (around days 80-85), when AAOD values and $\mathrm{HCHO}, \mathrm{CHOCHO}$, and $\mathrm{NO}_{2}$ concentrations were synchronously high. From Fig. 1, positive correlations among them are suggested.

In Fig. 2, CHOCHO concentrations, ratios of $\mathrm{CHOCHO}$ to $\mathrm{HCHO}$ concentrations $\left(R_{\mathrm{GF}}\right), \mathrm{NO}_{2}$ concentrations, and AAOD values are plotted against the HCHO concentration. The $R_{\mathrm{GF}}$ is important for atmospheric chemistry as it would vary responding to different VOC emissions such as BB and biogenic activities (e.g., Hoque et al., 2018a, b). HCHO was chosen as a standard since its lifetime was likely comparable to or longer than the other two potential BB-originating trace gases investigated here (i.e., $\mathrm{CHOCHO}$ and $\mathrm{NO}_{2}$ ) (e.g., Li et al., 2013) and its variation range was larger than that of the other two (Figs. 1 and 2). We found moderate tight correlations between $\mathrm{CHOCHO}$ and $\mathrm{HCHO}$ concentrations (a determination coefficient $R^{2}$ of $\sim 0.5$ for linear fit). As the $\mathrm{HCHO}$ concentration tripled from 3 to $9 \mathrm{ppbv}$, the $R_{\mathrm{GF}}$ decreased from $\sim 0.04$ to $\sim 0.03$ and the $\mathrm{NO}_{2}$ concentration doubled from $\sim 0.6$ to $\sim 1.2 \mathrm{ppbv}$, responding presumably to the increased contribution of VOC emissions from $\mathrm{BB}$. The $R_{\mathrm{GF}}$ values are slightly greater than those reported by Hoque et al. (2018a, b), whose statistics included data taken in the early morning and late evening, when $R_{\mathrm{GF}}$ values tended to be low compared to midday values analyzed in the present study. At a HCHO concentration of $9 \mathrm{ppbv}$, AAOD at $340 \mathrm{~nm}$ reached as high as $\sim 0.15 \pm 0.03$. Much larger AAODs were seen at a $\mathrm{HCHO}$ concentration higher than 9 ppbv (Fig. 2). These results provide strong observational evidence that aerosols in BB plumes (i.e., POA and SOA) absorb UV radiation significantly. In addition, Fig. 2 reveals that $\mathrm{HCHO}$ is a good tracer for absorption aerosols from $\mathrm{BB}$, reflecting that $\mathrm{BB}$ caused clear enhancements of both $\mathrm{HCHO}$ and absorption aerosols, when $\mathrm{BB}$ was the dominant source of $\mathrm{HCHO}$ and absorption aerosols over other sources.

While BC has been shown to have an AAE of about unity in literature, $\mathrm{AAE}$ values greater than unity are interpreted as $\mathrm{BrC}$ (e.g., Kirchstetter et al., 2004). For the whole period from January to April 2016, the mean AAE was estimated to be $1.57 \pm 0.28$ for the entire wavelength region from 340 to $870 \mathrm{~nm}$ (Fig. 3). Only for a shorter-wavelength range from

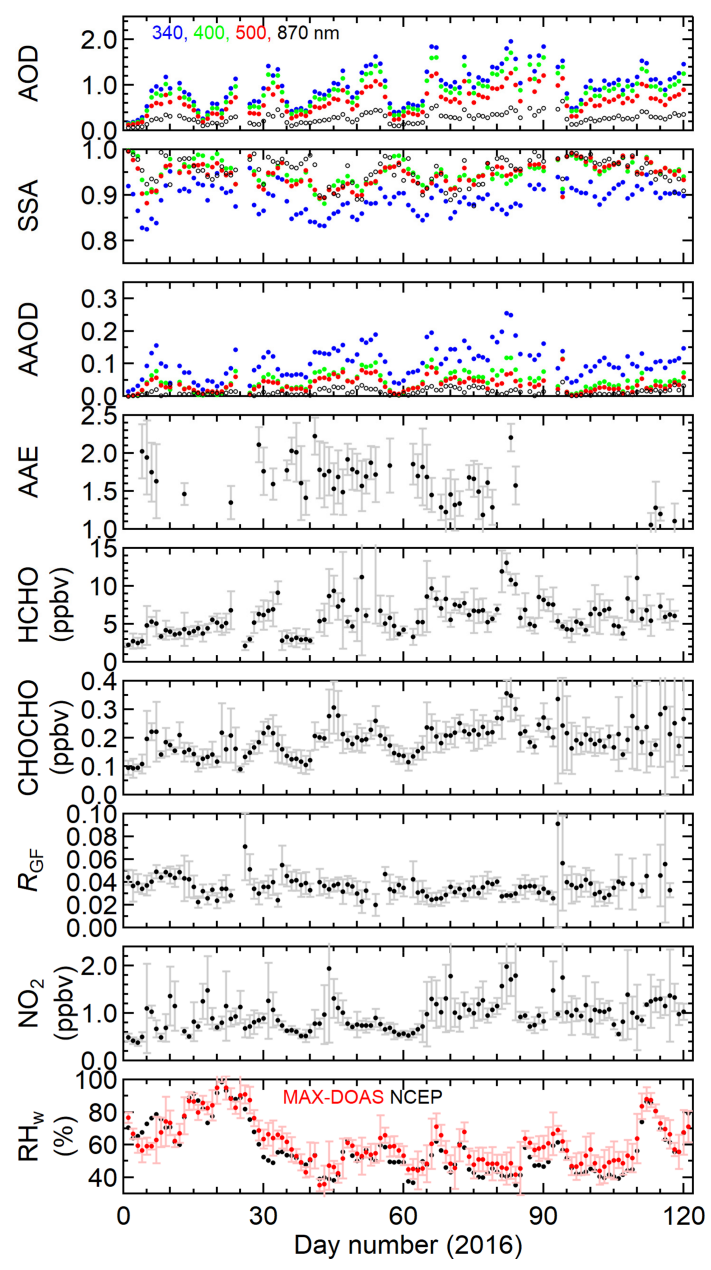

Figure 1. Time series of multiple components retrieved from sky radiometer and MAX-DOAS observations at Phimai, Thailand, for the intense BB period from January to April 2016. Daily means for 09:00-15:00 LT are plotted. Their $1 \sigma$ standard deviations are shown by error bars. AOD, SSA, and AAOD values for different wavelengths are shown in different colors. For $\mathrm{RH}_{\mathrm{W}}$, red symbols indicate MAX-DOAS-derived $\mathrm{RH}_{\mathrm{W}}$ for a layer of $0-1 \mathrm{~km}$ and black symbols indicate the surface $\mathrm{RH}_{\mathrm{W}}$ from NCEP data.

340 to $500 \mathrm{~nm}$, the mean AAE was estimated to be $1.93 \pm$ 0.59 (Fig. 3). A larger AAE for a shorter-wavelength range was also reported by Chakrabarty et al. (2010) for $\mathrm{BrC}$ in tar balls from smoldering biomass combustion. Also shown in Fig. 3 are data of the imaginary part of the refractive index $(k)$ retrieved from sky radiometer observations, indicating a strong wavelength dependence. The wavelength dependence was quantified similarly to Eq. (3) as the slope $(w)$ of the linear fit of $\ln (k)$ versus $\ln (\lambda)$. The $k$ values in the UV region were as high as $0.01-0.03$ but 1 order of magnitude smaller than that of $\mathrm{BC}(\sim 0.71)$ (Bond and Bergstrom, 2005). Using the parameterization derived by Saleh et al. (2014) and the $k$ value at $550 \mathrm{~nm}\left(k_{550}\right)$ derived by interpolation in the present study $(\sim 0.012)$, the BC-to-OA ratio of the emissions from 

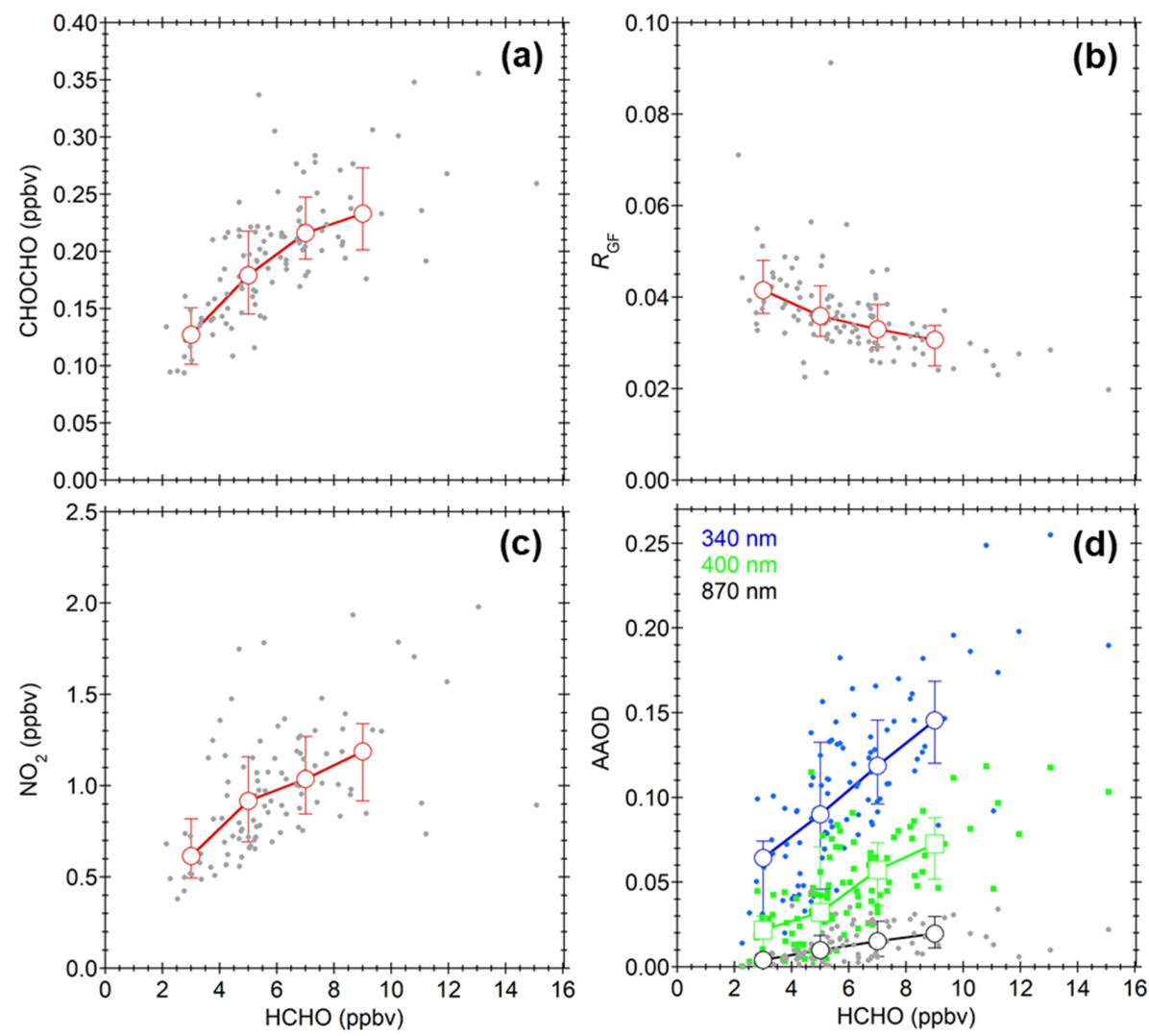

Figure 2. (a) $\mathrm{CHOCHO}$ concentration, (b) $R_{\mathrm{GF}}$, (c) $\mathrm{NO}_{2}$ concentration, and (d) AAOD values plotted as a function of $\mathrm{HCHO}$ concentration. AAOD values at 340, 400, and $870 \mathrm{~nm}$ are shown in blue, green, and black, respectively. The medians of respective quantities for each 2 ppbv bin of HCHO concentration are shown by open symbols. Error bars represent $67 \%$ ranges.
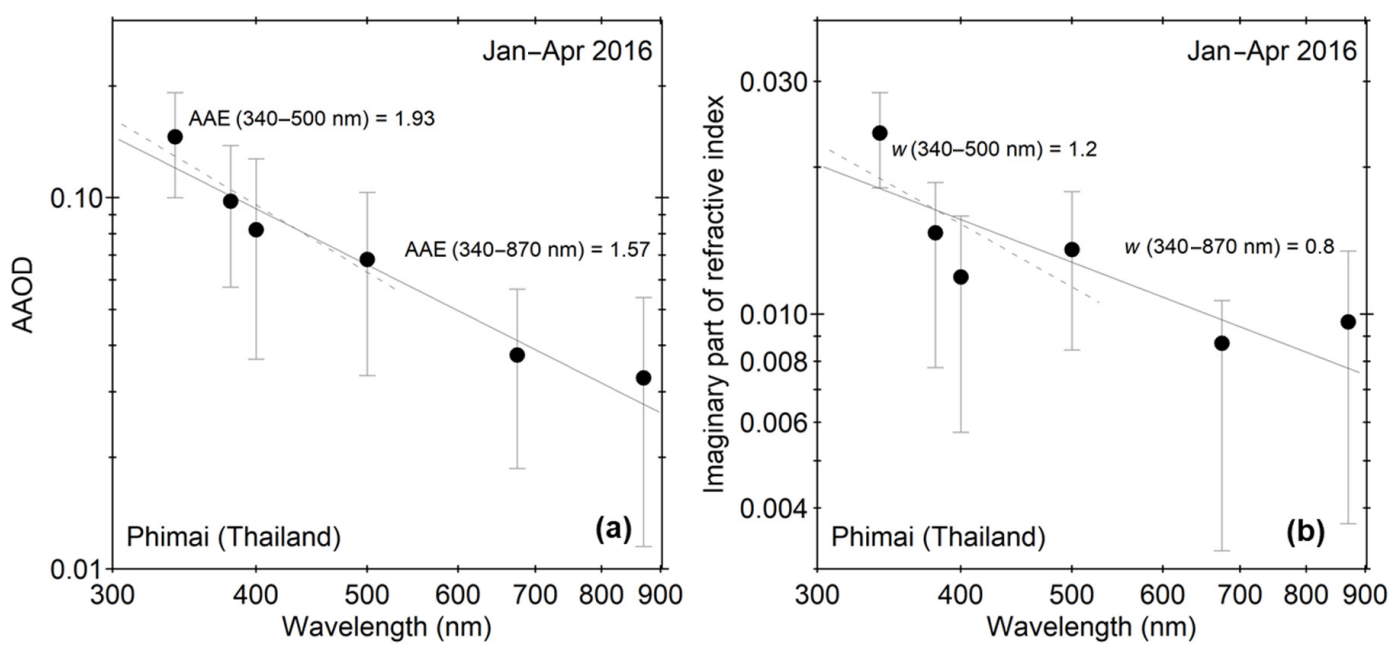

Figure 3. Spectra of (a) AAOD and (b) the imaginary part of refractive index for the period from January to April 2016. The power-law fitting results for 340-870 and 340-500 $\mathrm{nm}$ are shown by solid and dashed lines, respectively. Error bars represent $1 \sigma$ standard deviations for each wavelength. 
$\mathrm{BB}\left(R_{\mathrm{BC} / \mathrm{OA}}\right)$ around Phimai was estimated to be $1.9 \%$. A $R_{\mathrm{BC} / \mathrm{OA}}$ ratio of less than $1.9 \%$ is suggested for smoldering combustion of duffs investigated by Chakrabarty et al. (2010) as their $k_{550}$ value is smaller than that estimated for Phimai in the present study.

Since $\mathrm{HCHO}$ is a good tracer for absorption aerosols from $\mathrm{BB}$ as mentioned above, it is interesting to investigate the dependence of AAE on the HCHO concentration. We found, however, that their correlations were weak and the AAE at a $\mathrm{HCHO}$ of $3 \mathrm{ppbv}(\sim 1.7)$ tended to be higher than the AAE values at higher $\mathrm{HCHO}$ concentrations $(\sim 1.5)$ (Fig. 4). Although uncertainty in the estimate for the single datum of daily mean AAE was as large as $0.3-0.5$, it can be seen that AAE tended to converge to $1.5 \pm 0.2$ at a higher $\mathrm{HCHO}$ concentration in BB plumes.

According to smog chamber experiments by Saleh et al. (2014), aerosol absorptivity depends largely on burn conditions, not fuel type. In addition, the size distribution and the mixing state of $\mathrm{BC}$ and $\mathrm{OA}$ can be important factors for AAE (e.g., Russel et al., 2010; Kirchstetter et al., 2004). It was also reported that non-absorbing shells over BC cores can lead to an AAE greater or less than unity (Gyawali et al., 2009). Despite such a complexity in interpretation of the variation in AAE and the uncertainty in sky-radiometerretrieved AAE as large as $0.3-0.5$, we attempted to interpret possible enhancement in $\mathrm{AAE}$ at a $\mathrm{HCHO}$ of $3 \mathrm{ppbv}$. For this, using the parameterization of Salah et al. (2014) and the $k_{550}$ values, the $R_{\mathrm{BC} / \mathrm{OC}}$ ratio for a low $\mathrm{HCHO}$ case at $3 \mathrm{ppbv}$ was calculated to be 0.013 , which was smaller than the $R_{\mathrm{BC} / \mathrm{OC}}$ ratios at higher $\mathrm{HCHO}$ concentrations (e.g., 0.023 at a $\mathrm{HCHO}$ of 9 ppbv) (Fig. 4). A smaller $R_{\mathrm{BC} / \mathrm{OC}}$ ratio can be attributed to the lower-temperature $\mathrm{BB}$. In this case, the lower-temperature BB could yield only small values of AOD, AAOD, HCHO, and CHOCHO (i.e., the magnitude of $\mathrm{BB}$ emissions was weak) but a high value of AAE of about 1.7 (i.e., as a result of a smaller $R_{\mathrm{BC} / \mathrm{OA}}$ ratio for emissions) (Fig. 4). The other interpretation for the enhancement in AAE at a $\mathrm{HCHO}$ of 3 ppbv is that we observed more photochemically aged BB plumes at smaller HCHO concentrations. As the photochemical aging occurred, more SOA should have been produced, leading to stronger wavelength dependence of absorption. Considering a large uncertainty in AAE data used here, further investigation using more data from our multicomponent observations with a sky radiometer and MAX-DOAS is encouraged to better interpret the characteristics of BB plumes observed in this study. In addition, the results presented here are expected to be unique constraints for understanding physical-chemical-optical properties of BB plumes.

\section{Conclusions}

We conducted ground-based remote-sensing observations using a sky radiometer and MAX-DOAS at the SKYNET Phi-

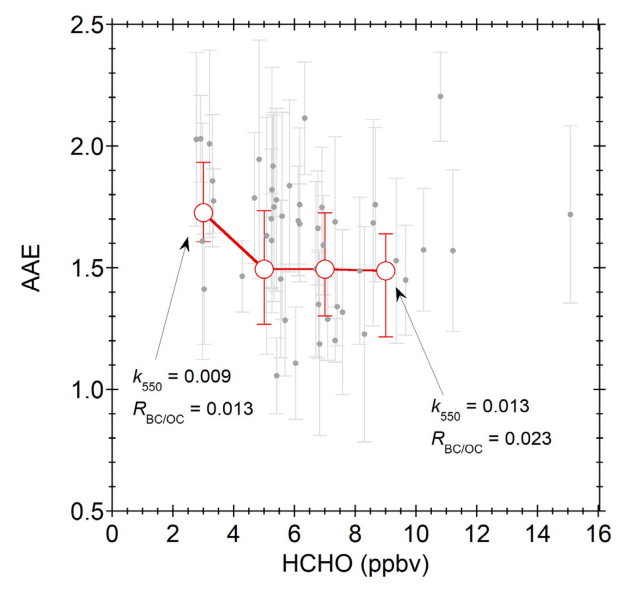

Figure 4. AAE values plotted as a function of $\mathrm{HCHO}$ concentration.

mai site in central Thailand from January to April 2016 to characterize optical properties of aerosols and organic gas concentrations in BB plumes. We found that the $\mathrm{HCHO}$ concentration for a layer of $0-1 \mathrm{~km}$ retrieved from MAX-DOAS was a useful tracer for absorption aerosols from BB plumes, when $\mathrm{BB}$ was the dominant source of HCHO and absorption aerosols over other sources. As the HCHO concentration tripled from 3 to $9 \mathrm{ppbv}$, the $R_{\mathrm{GF}}$ decreased from $\sim 0.04$ to $\sim 0.03$, in response presumably to the increased contribution of VOC emissions from BB. In addition, AAODs increased with $\mathrm{HCHO}$. At a $\mathrm{HCHO}$ of $9 \mathrm{ppbv}$, AAOD at $340 \mathrm{~nm}$ reached as high as $\sim 0.15 \pm 0.03$. The AAE at 340$870 \mathrm{~nm}$ was about $1.5 \pm 0.2$, indicating the presence of $\mathrm{BrC}$ aerosols. The results from our multicomponent observations around central Thailand are expected to be unique constraints for understanding physical-chemical-optical properties of BB plumes.

Code and data availability. The data and codes are available upon request to the corresponding author (hitoshi.irie@chiba-u.jp). The sky radiometer and MAX-DOAS data are also available at http:// atmos3.cr.chiba-u.jp/skynet/ (last access: 29 January 2019).

Author contributions. HI designed the present study, performed observation and analysis, and wrote the paper, with support from all the authors. HMSH analyzed MAX-DOAS data. HO and AMF analyzed sky radiometer data. TT and TJ supported observation at Phimai. AD and $\mathrm{PH}$ gave useful comments.

Competing interests. The authors declare that they have no conflict of interest.

Special issue statement. This article is part of the special issue "SKYNET - the international network for aerosol, clouds, and so- 
lar radiation studies and their applications (AMT/ACP inter-journal SI)". It is not associated with a conference.

Acknowledgements. Support from Vijak Pangsapa and the Bureau of Royal Rainmaking in Agricultural Aviaion (BRRAA) is gratefully acknowledged. This work was supported by JSPS KAKENHI grant number JP16K00512, JSPS KAKENHI grant number JP15H01728, and JST CREST grant number JPMJCR15K4.

Edited by: Omar Torres

Reviewed by: two anonymous referees

\section{References}

Bond, T. C. and Bergstrom, R. W.: Light absorption by carbonaceous particles: an investigative review, Aerosol Sci. Tech., 39, 1-40, 2005.

Bond, T. C., Doherty, S. J., Fahey, D. W., Forster, P. M., Berntsen, T., DeAngelo, B. J., Flanner, M. G., Ghan, S., Kärcher, B., Koch, D., Kinne, S., Kondo, Y., Quinn, P. K., Sarofim, M. C., Schultz, M. G., Schulz, M., Venkataraman, C., Zhang, H., Zhang, S., Bellouin, N., Guttikunda, S. K., Hopke, P. K., Jacobson, M. Z., Kaiser, J. W., Klimont, Z., Lohmann, U., Schwarz, J. P., Shindell, D., Storelvmo, T., Warren, S. G., and Zender, C. S.: Bounding the role of black carbon in the climate system: A scientific assessment, J. Geophys. Res.-Atmos., 118, 5380-5552, https://doi.org/10.1002/jgrd.50171, 2013.

Campanelli, M., Estelles, V., Tomasi, C., Nakajima, T., Malvestuto, V., and Martinez-Lozano, J. A.: Application of the SKYRAD improved Langley plot method for the in situ calibration of CIMEL sun-sky photometers, Appl. Optics, 46, 2688-2702, 2007.

Chakrabarty, R. K., Moosmüller, H., Chen, L.-W. A., Lewis, K., Arnott, W. P., Mazzoleni, C., Dubey, M. K., Wold, C. E., Hao, W. M., and Kreidenweis, S. M.: Brown carbon in tar balls from smoldering biomass combustion, Atmos. Chem. Phys., 10, 63636370, https://doi.org/10.5194/acp-10-6363-2010, 2010.

Gyawali, M., Arnott, W. P., Lewis, K., and Moosmüller, H.: In situ aerosol optics in Reno, NV, USA during and after the summer 2008 California wildfires and the influence of absorbing and nonabsorbing organic coatings on spectral light absorption, Atmos. Chem. Phys., 9, 8007-8015, https://doi.org/10.5194/acp-9-80072009, 2009.

Hammer, M. S., Martin, R. V., van Donkelaar, A., Buchard, V., Torres, O., Ridley, D. A., and Spurr, R. J. D.: Interpreting the ultraviolet aerosol index observed with the OMI satellite instrument to understand absorption by organic aerosols: implications for atmospheric oxidation and direct radiative effects, Atmos. Chem. Phys., 16, 2507-2523, https://doi.org/10.5194/acp16-2507-2016, 2016.

Hashimoto, M., Nakajima, T., Dubovik, O., Campanelli, M., Che, H., Khatri, P., Takamura, T., and Pandithurai, G.: Development of a new data-processing method for SKYNET sky radiometer observations, Atmos. Meas. Tech., 5, 2723-2737, https://doi.org/10.5194/amt-5-2723-2012, 2012.

Hönninger, G. and Platt, U.: Observations of $\mathrm{BrO}$ and its vertical distribution during surface ozone depletion at Alert, Atmos. Environ., 36, 2481-2489, 2002.
Hönninger, G., von Friedeburg, C., and Platt, U.: Multi axis differential optical absorption spectroscopy (MAX-DOAS), Atmos. Chem. Phys., 4, 231-254, https://doi.org/10.5194/acp-4231-2004, 2004.

Hoque, H. M. S., Irie, H., and Damiani, A.: First MAX-DOAS observations of formaldehyde and glyoxal in Phimai, Thailand, J. Geophys. Res., 123, 17, https://doi.org/10.1029/2018JD028480, 2018a.

Hoque, H. M. S., Irie, H., Damiani, A., Rawat, P., and Naja, M.: First simultaneous observations of formaldehyde and glyoxal by MAX-DOAS in the Indo-Gangetic Plain region, SOLA, 14, 159164, https://doi.org/10.2151/sola.2018-028, 2018 b.

IPCC: Summary for Policymakers, in: Climate Change 2013: The Physical Science Basis. Contribution of Working Group I to the Fifth Assessment Report of the Intergovernmental Panel on Climate Change, edited by: Stocker, T. F., Qin, D., Plattner, G.-K., Tignor, M., Allen, S. K., Boschung, J., Nauels, A., Xia, Y., Bex, V., and Midgley, P. M., Cambridge University Press, Cambridge, UK and New York, NY, USA, 2013.

Irie, H., Kanaya, Y., Akimoto, H., Iwabuchi, H., Shimizu, A., and Aoki, K.: First retrieval of tropospheric aerosol profiles using MAX-DOAS and comparison with lidar and sky radiometer measurements, Atmos. Chem. Phys., 8, 341-350, https://doi.org/10.5194/acp-8-341-2008, 2008.

Irie, H., Takashima, H., Kanaya, Y., Boersma, K. F., Gast, L., Wittrock, F., Brunner, D., Zhou, Y., and Van Roozendael, M.: Eight-component retrievals from ground-based MAXDOAS observations, Atmos. Meas. Tech., 4, 1027-1044, https://doi.org/10.5194/amt-4-1027-2011, 2011.

Irie, H., Nakayama, T., Shimizu, A., Yamazaki, A., Nagai, T., Uchiyama, A., Zaizen, Y., Kagamitani, S., and Matsumi, Y.: Evaluation of MAX-DOAS aerosol retrievals by coincident observations using CRDS, lidar, and sky radiometer inTsukuba, Japan, Atmos. Meas. Tech., 8, 2775-2788, https://doi.org/10.5194/amt-8-2775-2015, 2015.

Khatri, P. and Takamura, T.: An algorithm to screen cloud affected data for sky radiometer data analysis, J. Meteor. Soc. Jpn., 87, 189-204, 2009.

Khatri, P., Takamura, T., Nakajima, T., Estellés, V., Irie, H., Kuze, H., Campanelli, M., Sinyuk, A., Lee, S. -M., Sohn, B. J., Padhithurai, G., Kim, S. -W., Yoon, S. C., Lozano, J. A. M., Hashimoto, M., Devara, P. C. S., and Manago, N.: Factors for inconsistent aerosol single scattering albedo between SKYNET and AERONET, J. Geophys. Res., 121, 1859-1877, https://doi.org/10.1002/2015JD023976, 2016.

Kirchstetter, T. W., Novakov, T., and Hobbs, P. V.: Evidence that the spectral dependence of light absorption by aerosols is affected by organic carbon, J. Geophys. Res., 109, D21208, https://doi.org/10.1029/2004JD004999, 2004.

Li, X., Brauers, T., Hofzumahaus, A., Lu, K., Li, Y. P., Shao, M., Wagner, T., and Wahner, A.: MAX-DOAS measurements of $\mathrm{NO}_{2}, \mathrm{HCHO}$ and $\mathrm{CHOCHO}$ at a rural site in Southern China, Atmos. Chem. Phys., 13, 2133-2151, https://doi.org/10.5194/acp13-2133-2013, 2013.

Mok, J., Krotkov, N. A., Torres, O., Jethva, H., Li, Z., Kim, J., Koo, J.-H., Go, S., Irie, H., Labow, G., Eck, T. F., Holben, B. N., Herman, J., Loughman, R. P., Spinei, E., Lee, S. S., Khatri, P., and Campanelli, M.: Comparisons of spectral aerosol single scatter- 
ing albedo in Seoul, South Korea, Atmos. Meas. Tech., 11, 22952311, https://doi.org/10.5194/amt-11-2295-2018, 2018.

Myhre, G., Samset, B. H., Schulz, M., Balkanski, Y., Bauer, S., Berntsen, T. K., Bian, H., Bellouin, N., Chin, M., Diehl, T., Easter, R. C., Feichter, J., Ghan, S. J., Hauglustaine, D., Iversen, T., Kinne, S., Kirkevåg, A., Lamarque, J.-F., Lin, G., Liu, X., Lund, M. T., Luo, G., Ma, X., van Noije, T., Penner, J. E., Rasch, P. J., Ruiz, A., Seland, Ø., Skeie, R. B., Stier, P., Takemura, T., Tsigaridis, K., Wang, P., Wang, Z., Xu, L., Yu, H., Yu, F., Yoon, J.-H., Zhang, K., Zhang, H., and Zhou, C.: Radiative forcing of the direct aerosol effect from AeroCom Phase II simulations, Atmos. Chem. Phys., 13, 1853-1877, https://doi.org/10.5194/acp13-1853-2013, 2013.

Nakajima, T., Tonna, G., Rao, R., Kaufman, Y., and Holben, B.: Use of sky brightness measurements from ground for remote sensing of particulate polydispersions, Appl. Optics, 35, 2672-2686, 1996.

Nakajima, T., Yoon, S. C., Ramanathan, V., Shi, G. Y., Takemura, T., Higurashi, A., Takamura, T., Aoki, K., Sohn, B. J., Kim, S. W., Tsuruta, H., Sugimoto, N., Shimizu, A., Tanimoto, H., Sawa, Y., Lin, N. H., Lee, C. T., Goto, D., and Schutgens, N.: Overview of the Atmospheric Brown Cloud East Asian Regional Experiment 2005 and a study of the aerosol direct radiative forcing in east Asia, J. Geophys. Res., 112, D24S91, https://doi.org/10.1029/2007JD009009, 2007.
Platt, U. and Stutz, J.: Differential Optical Absorption spectroscopy, Principles and Applications, XV, 597 pp., 272 illus., 29 in color, Physics of Earth and Space Environments, Springer, Berlin, Germany, ISBN 978-3-540-21193-8, 2008.

Russell, P. B., Bergstrom, R. W., Shinozuka, Y., Clarke, A. D., DeCarlo, P. F., Jimenez, J. L., Livingston, J. M., Redemann, J., Dubovik, O., and Strawa, A.: Absorption Angstrom Exponent in AERONET and related data as an indicator of aerosol composition, Atmos. Chem. Phys., 10, 1155-1169, https://doi.org/10.5194/acp-10-1155-2010, 2010.

Saleh, R., Robinson, E. S., Tkacik, D. S., Ahern, A. T., Liu, S., Aiken, A. C., Sullivan, R. C., Presto, A. A., Dubey, M. K., Yokelson, R. J., Donahue, N. M., and Robinson, A. L.: Brownness of organics in aerosols from biomass burning linked to their black carbon content, Nat. Geosci., 7, 647-650, https://doi.org/10.1038/ngeo2220, 2014.

Takamura, T. and Nakajima, T.: Overview of SKYNET and its activities, Opt. Pura Apl. 37, 3303-3308, 2004.

Uchiyama, A., Matsunaga, T., and Yamazaki, A.: The instrument constant of sky radiometers (POM-02) - Part 2: Solid view angle, Atmos. Meas. Tech., 11, 5389-5402, https://doi.org/10.5194/amt-11-5389-2018, 2018. 